\title{
Automatische detectie van convulsieve aanvallen met video
}

Gevaarlijke epileptische aanvallen automatisch detecteren zonder apparaten en draden aan of bij de persoon? Het kan met een simpele videocamera en een algoritme, of rekenprogramma, dat de beelden analyseert. In een recente studie lieten onderzoekers hun algoritme los op lange, ononderbroken video-opnames met daarin een groot aantal epileptische aanvallen die in de thuissituatie werden geregistreerd. Ze lieten zien dat het algoritme gevaarlijke epileptische aanvallen in de nacht kan detecteren en mogelijk de veiligheid van mensen met deze aanvallen kan vergroten.

Mensen hebben hulp nodig als ze gevaarlijke (bijvoorbeeld convulsieve) aanvallen hebben, maar kunnen daar zelf niet om vragen. Deze aanvallen kunnen daarom gevaarlijke situaties opleveren, vooral als dit's nachts gebeurt bij mensen die alleen zijn. Er bestaan apparaten die gebruikt kunnen worden om automatisch aanvallen te detecteren en iemand te alarmeren. Met de op dit moment beschikbare hulpmiddelen kan helaas maar een deel van de mensen geholpen worden. Draagbare detectiehulpmiddelen (wearables) kunnen bijvoorbeeld niet door sommige kinderen en verstandelijk beperkten gebruikt worden. Daarom ontwikkelden onderzoekers van Stichting Epilepsie Instellingen Nederland (SEIN), Universitair Medisch Centrum Utrecht (UMCU) en Kempenhaeghe een algoritme om aanvallen te detecteren met een videocamera. Recentelijk onderzochten zij of het algoritme in de praktijk goed zou werken.

\section{Hoe het onderzoek werd uitgevoerd}

In een eerder onderzoek werd door de onderzoeksgroep een algoritme voor detectie van convulsieve aanvallen met video ontwikkeld (Kalitzin et al., 20I2). Het algoritme meet de aanwezigheid van ritmische bewegingen tussen 2 en $6 \mathrm{~Hz}$. Deze frequentie is typisch voor het trillen aan het eind van de tonische fase en de snelle schokken die daarop volgen in de clonische fase van een tonisch-clonische aanval. In figuur $\mathrm{I}$ is een voorbeeld van de output van het algoritme ten tijde van een convulsieve aanval te zien. In het huidige onderzoek werden de instellingen van het algoritme geoptimaliseerd voor een goede verhouding tussen de sensitiviteit voor de detectie van de aanvallen en een laag aantal valse alarmen. Vervolgens werd de performance van het algoritme gemeten.

De optimale afkapwaarde voor output-waarden van het algoritme om een detectie te genereren werd berekend in een training dataset met 72 convulsieve aanvallen gemeten bij 50 mensen met epilepsie, in de epilepsie monitoring unit van SEIN. Deze afkapwaarde was de minimale outputwaarde waarbij een sensitiviteit van 90\% of hoger bereikt werd. Vervolgens lieten de onderzoekers het geoptimaliseerde algoritme los op een nieuwe test-dataset die bestond uit twee delen. Het eerste deel had video's van 24 volledige nachten (8-I5 uur) in twaalf deelnemers met nachtelijke

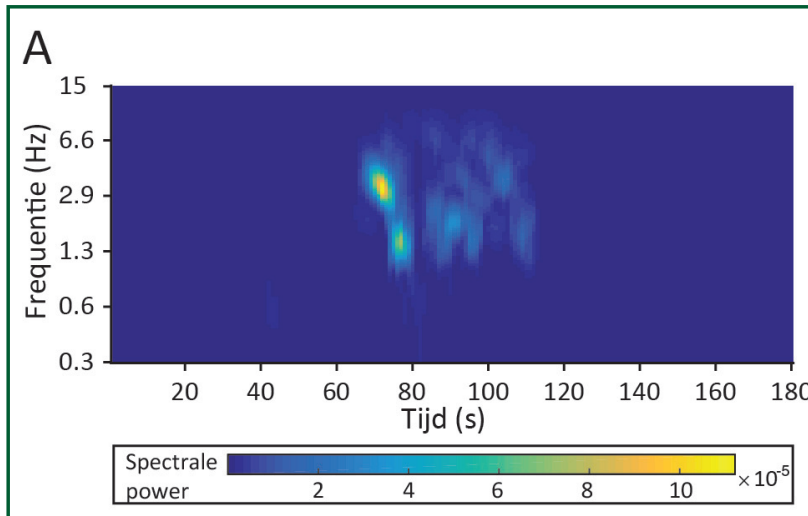

B

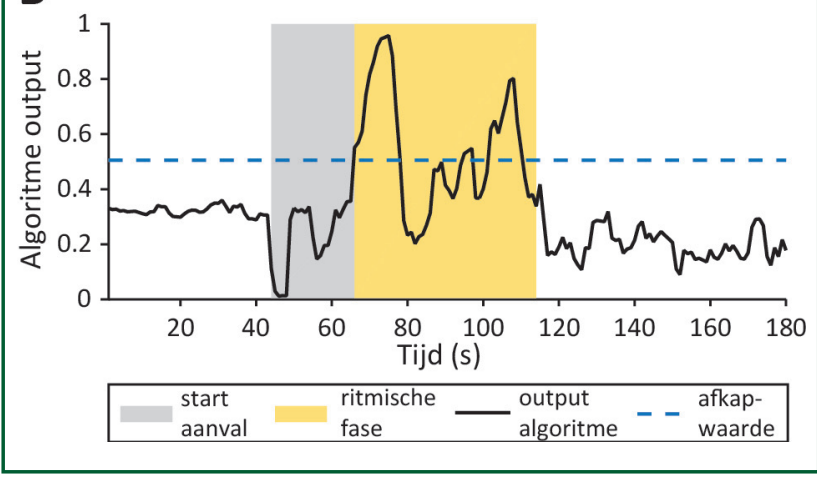

Figuur 1 Voorbeeld van de algoritme-output ten tijde van een convulsieve aanval. A) Tijd-frequentieplot van een stukje video, met vanaf ongeveer 65 seconden de ritmische fase van de aanval. B) De (eenheidsloze) output van het algoritme overschrijdt de afkapwaarde vlak na de start van de ritmische fase van de aanval. Een detectie wordt gegenereerd als de algoritme-output twee seconden achtereen boven de afkapwaarde komt. 
aanvallen, geregistreerd in hun woning. In deze ononderbroken, willekeurig gekozen video's onderzochten zij het optreden van valse alarmen. Verder onderzochten zij de sensitiviteit en de detectiesnelheid van het algoritme in het tweede deel van de testset, met daarin 50 kortere video's (3o min) met in elke video een convulsieve aanval. Start en eind van aanvallen en de ritmische fasen (trillen/ schokken) van de aanvallen werden geannoteerd op basis van de video. Aanvalstype werd bepaald door middel van consensus door twee neurologen.

\section{Testresulltaten}

Het algoritme detecteerde alle 50 aanvallen en had dus een sensitiviteit van $100 \%$. In figuur 2 is de reactiesnelheid van het algoritme te zien voor alle aanvallen. Meer dan driekwart van de aanvallen werd al binnen tien seconden na de start van de ritmische fase gedetecteerd. Ook aanvallen onder de dekens zijn geen probleem voor het algoritme; deze worden net zo goed en snel gedetecteerd als aanvallen waarbij de persoon goed te zien is. Daarnaast werden ook sommige andere aanvalstypen die zorg behoeven door het algoritme gedetecteerd: drie van de vijf hyperkinetische aanvallen en zes van de negen andere grote aanvallen.

De mediaan van het aantal valse detecties per nacht was 0,78 . In meer dan de helft van de nachten was er minder dan één vals-positieve detectie, waarvan er in negen nachten geen vals-positieve detectie was. In vier nachten waren er meer dan vijf vals-positieve detecties. Deze detecties werden veroorzaakt door herhaaldelijk voorkomende vrijwillige en onvrijwillige ritmische bewegingen tijdens waak, zoals krabben of myoclonieën waarbij ledematen op het matras stuiterden.

\section{Conclusie}

Het door de onderzoeksgroep ontwikkelde algoritme kan gebruikt worden om convulsieve aanvallen in de nacht tijdig met een videocamera te detecteren. Er zijn nauwelijks vals-positieve detecties. De meeste valse alarmen zijn in de toekomst mogelijk te voorkomen door het algoritme slimmer te maken. Hierover is meer te lezen in het artikel dat recent verscheen in Epilepsia (Geertsema et al., 20I8). Het detectiealgoritme zal in de toekomst mogelijk deel uit

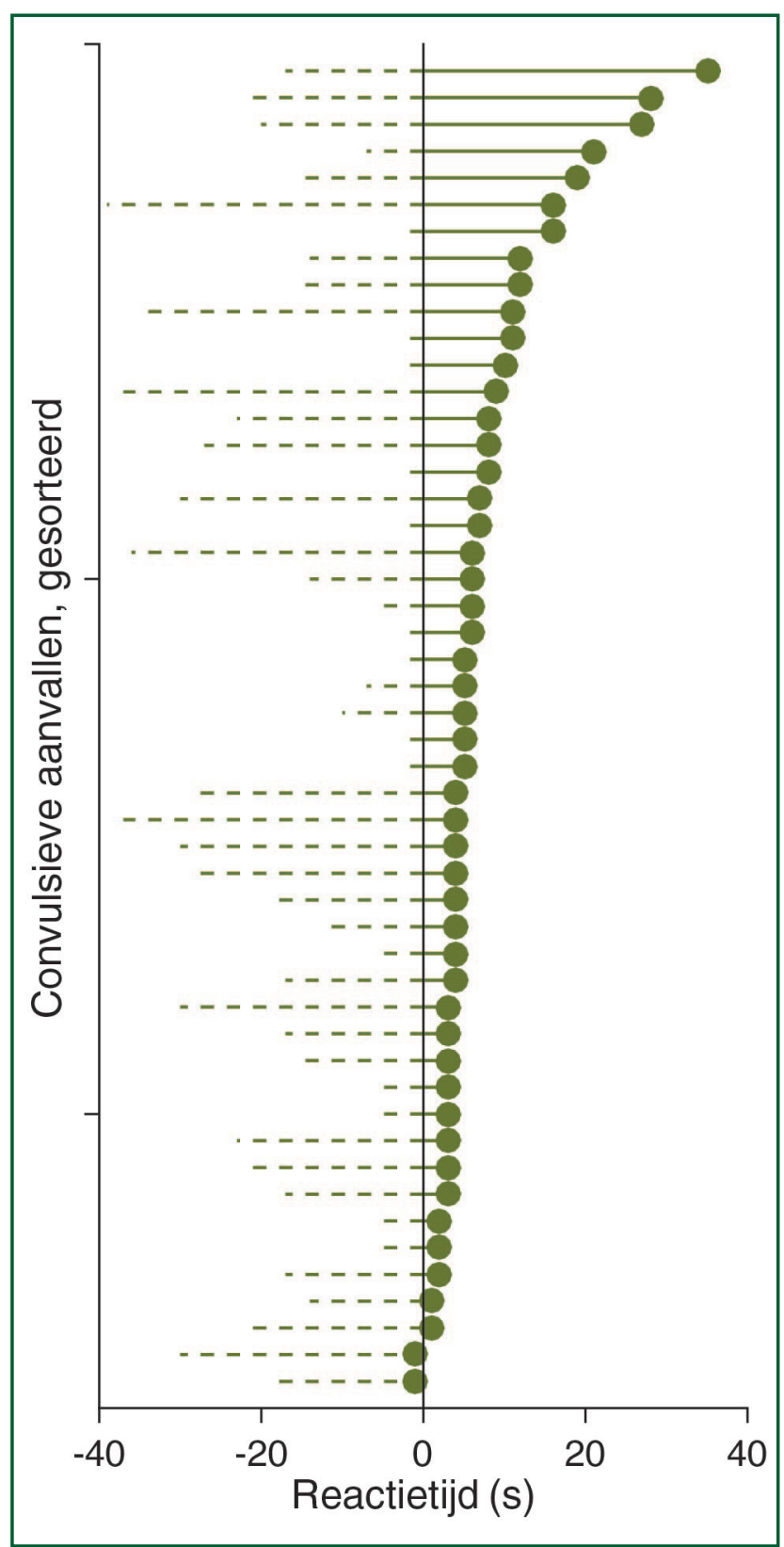

Figuur 2 Reactietijd van het algoritme op alle 50 convulsieve aanvallen in de testset. De cirkels geven het detectiemoment aan, berekend vanaf het begin van de ritmische fase (bij nul seconden). De stippellijnen geven het begin van de aanval, vóór de ritmische fase, aan. Deze tijdsduur kan een focaal begin van de aanval bevatten.

gaan maken van een contactloos systeem dat ook vallen en apneus kan detecteren.

\title{
Nationaal Epilepsie Symposium
}

\author{
I6 november 2018 | Jaarbeurs, Utrecht \\ Informatie: communicatie@epilepsiefonds.nl
}

